\title{
Effect of randomized supplementation with high dose olive, flax or fish oil on serum phospholipid fatty acid levels in adults with attention deficit hyperactivity disorder
}

\author{
Genevieve S. YounG ${ }^{\mathrm{a}}$, Julie A. CONQUER ${ }^{\mathrm{a} *}$, René THOMAS ${ }^{\mathrm{b}}$

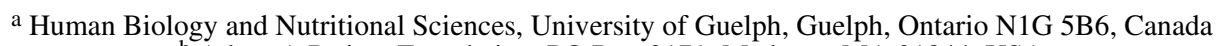 \\ $\mathrm{b}$ Adopt A Patient Foundation, PO Box 2171, Methuen, MA 01844, USA
}

(Received 16 October 2004; accepted 21 December 2004)

\begin{abstract}
Dietary intake of omega-3 fatty acids has been positively correlated with cardiovascular and neuropsychiatric health in several studies. The high seafood intake by the Japanese and Greenland Inuit has resulted in low ratios of the omega- 6 fatty acid arachidonic acid (AA, 20:4n-6) to eicosapentaenoic acid (EPA, 20:5n-3), with the Japanese showing AA:EPA ratios of approximately 1.7 and the Greenland Eskimos showing ratios of approximately 0.14 . It was the objective of this study to determine the effect of supplementation with high doses $(60 \mathrm{~g})$ of flax and fish oils on the blood phospholipid (PL) fatty acid status, and AA/EPA ratio of individuals with Attention Deficit Hyperactivity Disorder (ADHD), commonly associated with decreased blood omega-3 fatty acid levels. Thirty adults with ADHD were randomized to 12 weeks of supplementation with olive oil ( $<1 \%$ omega-3 fatty acids), flax oil (source of alpha-linolenic acid; 18:3n-3; $\alpha$-LNA) or fish oil (source of EPA and docosahexaenoic acid; 22:6n-3; DHA). Serum PL fatty acid levels were determined at baseline and at 12 weeks. Flax oil supplementation resulted in an increase in $\alpha$-LNA and a slight decrease in the ratio of AA/EPA, while fish oil supplementation resulted in increases in EPA, DHA and total omega-3 fatty acids and a decrease in the AA/EPA ratio to values seen in the Japanese population. These data suggest that in order to increase levels of EPA and DHA in adults with ADHD, and decrease the AA/EPA ratio to levels seen in high fish consuming populations, high dose fish oil may be preferable to high dose flax oil. Future study is warranted to determine whether correction of low levels of long-chain omega- 3 fatty acids is of therapeutic benefit in this population.
\end{abstract}

omega-3 fatty acids / fish oil / flax oil / attention deficit hyperactivity disorder / adults

Abbreviations: ADHD: Attention Deficit (Hyperactivity) Disorder; DHA: docosahexaenoic acid; EPA: eicosapentaenoic acid; LNA: linolenic acid; PL: phospholipids.

\section{INTRODUCTION}

The long-chain omega-3 polyunsaturated fatty acids (LCPUFA's) eicosapen- taenoic acid (EPA; 20:5n-3) and docosahexaenoic acid (DHA; 22:6n-3) are found in high concentrations in fish oil [1]. Dietary intake of these fatty acids has been

* Corresponding author: jconquer@uoguelph.ca 
positively correlated with health in several studies. For example, the low incidence of coronary heart disease (CHD) in Greenland Eskimos has been linked to their diet of marine food [2-4], and a similar association linking high rates of fish intake with low rates of death from CHD has also been observed in the Japanese [5, 6]. The Greenland Eskimos consume up to several thousand milligrams of EPA plus DHA each day [7] while the Japanese consume up to $1500 \mathrm{mg} \cdot \mathrm{day}^{-1}$ [8]. The high seafood intake in these groups has resulted in low ratios of the omega- 6 fatty acid arachidonic acid (AA, 20:4n-6) to EPA, with the Japanese showing AA:EPA ratios of approximately 1.7 and the Greenland Eskimos showing ratios of approximately 0.14 [9].

Dietary consumption of fish has also been linked to a variety of neuropsychiatric disorders. Epidemiological studies have suggested that high fish consumption is inversely associated with cognitive impairment, cognitive decline, and/or the development of dementia or Alzheimer's disease (AD) [10-14]. Similarly, societies consuming large amounts of fish and omega-3 fatty acids appear to have lower rates of major depression [15] and bipolar disease [16], and the likelihood of having depressive symptoms increases among infrequent fish consumers versus frequent fish consumers [17]. As evidence, the Japanese have been found to have very low rates of depression in a number of studies [18, 19]. Furthermore, there is increasing evidence that depression predisposes an individual to CHD [20], a condition which, as already established, shows an inverse relationship with consumption of dietary omega-3 fatty acids.

While a similar relationship between fish consumption and the neuropsychiatric disease attention deficit/hyperactivity disorder (ADHD) has not previously been observed, the levels of both EPA [21] and DHA [22, 23], have been found to be abnormal in children with ADHD. Similarly, adults with ADHD also show low levels of the long-chain polyunsaturated omega-3 fatty acid DHA [24]. There are conflicting reports in the literature about the cognitive benefits of omega-3 supplementation in patients with ADHD [25-27]. Normalizing levels of these fatty acids and reducing the $\mathrm{AA} / \mathrm{EPA}$ ratio to levels observed in populations such as the Greenland Eskimos and the Japanese should be beneficial due to the association of these fatty acids with various measures of health, including CHD, which is the main cause of death in Western industrialized countries, and depression, with which ADHD is frequently comorbid [28]. However, there are no peer-reviewed publications showing how omega-3 supplementation affects levels of blood fatty acids in this population. Furthermore, there are no studies comparing the ability of fish oil and flax oil to modify blood serum fatty acids in adults with diagnosed ADHD. The present study investigated the effect of consuming high doses of fish oil and flax oil on serum phospholipid fatty acid concentrations in adults with diagnosed ADHD. The objective was to raise levels of the longchain omega-3 polyunsaturated fatty acids, thereby reducing the AA/EPA ratio to levels comparable to that observed in populations consuming large quantities of marine food.

\section{MATERIALS AND METHODS}

Thirty subjects aged 18 to 65 reporting previous diagnoses with ADHD were recruited by advertisements and flyers in the local community. Inclusion criteria for ADHD subjects included a previous diagnosis of ADHD by a physician and the ability to give informed consent. Individuals were excluded if they had been diagnosed with a lipid metabolism or psychiatric disorder other than ADHD or if they used dietary supplements (other than vitamins/minerals) within the past month, omega- 3 fatty acid supplements within the past 6 months, or consumed fish greater than once per week. Subjects were also excluded if they 
had used a pharmaceutical agent to treat their condition within the past 2 weeks. This study was approved by the Research Ethics Board of the University of Guelph. After complete description of the study to the subjects, written informed consent was obtained.

Subjects were randomly assigned, using randomization tables, to receive supplementation for 12 weeks with $60 \mathrm{~g}$ per day of either liquid olive oil ( $<0.6 \mathrm{~g}$ omega-3 fatty acids), flax oil (36 $\mathrm{g}$ omega-3 fatty acids as $\alpha$-LNA) or fish oil (39 g omega-3 fatty acids as $\alpha$-LNA, EPA and DHA), in an open dosing manner. The fish oil was highly concentrated (38\% EPA and $20 \%$ DHA) and molecular distilled to result in trace levels only of heavy metals and pesticides. The three types of oil were in identical brown bottles. The level of dietary supplementation in this study would add an extra 540 calories per day, assuming no other dietary changes. Subjects were given suggestions as to how to incorporate the oil into their food, and were given the choice of whether to consume the oil by itself or with food. They were also given the choice of whether to distribute dosing throughout the day or take it all at one time. Two subjects in the fish oil group dropped out of the study prior to initiating supplementation for no specific reason. One subject in each of the flax oil and fish oil groups did not complete the study due to an inability to comply with the supplementation regimen. The results are for 10 subjects in the olive oil group, 9 subjects in the flax oil group and 7 subjects in the fish oil group. Care was taken that analyses of blood fatty acids were obtained by an unbiased third party (Lipid Analytical Laboratory, Guelph, Ontario, Canada).

Non-fasting venous blood was obtained by finger prick method. Whole blood was centrifuged at room temperature for $10 \mathrm{~min}$ at $1250 \times g$ and serum obtained. Serum was stored at $-20^{\circ} \mathrm{C}$ until further analysis. Both human serum and the oils were extracted using equal volumes of chloroform/methanol (2:1) in the presence of 17:0 internal
Table I. Baseline characteristics of subjects in olive oil, flax oil and fish oil Groups ${ }^{\mathrm{a}}$.

\begin{tabular}{lc}
\hline Characteristic & $(n=26)$ \\
\hline Age, y & $31.0 \pm 2.8(18-65)$ \\
EPA, $\%$ & $0.8 \pm 0.1(0.3-1.6)$ \\
DHA, $\%$ & $2.7 \pm 0.2(1.5-6.0)$ \\
$\mathrm{n}-6 / \mathrm{n}-3$ & $7.5 \pm 0.3(3.7-10.4)$ \\
\hline AA/EPA & $15.4 \pm 1.2(7.8-25.82)$ \\
\hline Sex $(\mathrm{M} / \mathrm{F})$ & $12 / 14$ \\
\hline
\end{tabular}

a Data represents mean \pm SEM for each characteristic. There were no significant differences between the three groups for baseline characteristics.

standard. Thin layer chromatography (TLC) was used to separate the lipid fraction, and samples run on a gas chromatograph (GC), at Lipid Analytical Laboratory as previously indicated [29]. The sum of fatty acids from 14:0 to $24: 1$ was taken as 100 and levels of individual fatty acids were expressed as a percentage of this sum.

Ages of the participants in each group were compared by ANOVA using SAS (SAS Institute, Cary, NC). Changes of individual fatty acids over time with supplementation were compared by ANOVA, followed by Tukey, also using SAS. The significance level was set at $P=0.05$. Values in tables are given for ANOVA. Letter superscripts denote differences by follow up Tukey's $t$-test if the ANOVA result was $P<0.05$. Human serum fatty acid data is presented as $\%$ of total fatty acids. Oil fatty acid data is presented as $\mathrm{g} \cdot 100 \mathrm{~g}^{-1}$.

\section{RESULTS}

Twenty-six subjects completed the study. As indicated in Table I, the average age of all participants was $31.0 \pm 2.8$ $($ mean $\pm \mathrm{SE})$. Baseline values for $\mathrm{EPA}$, DHA, n-6/n-3 and AA/EPA of all participants are also given in Table I. There were no significant differences between groups for baseline characteristics (data not shown). 
Table II. Omega-3 fatty acid levels of olive, flax and fish supplementary oils ${ }^{\mathrm{a}}$.

\begin{tabular}{lccc}
\hline Fatty acid & Olive oil & Flax oil & Fish oil \\
\hline C18:3n3 & 0.7 & 59.6 & 0.8 \\
C18:4n3 & 0.0 & 0.0 & 1.7 \\
C20:3n3 & 0.0 & 0.1 & 0.2 \\
C20:4n3 & 0.0 & 0.1 & 2.1 \\
C20:5n3 EPA & 0.0 & 0.0 & 37.5 \\
C22:5n3 & 0.0 & 0.0 & 3.2 \\
C22:6n3 DHA & 0.0 & 0.0 & 19.7 \\
Total Omega-3 & 0.7 & 59.8 & 65.3 \\
\hline
\end{tabular}

${ }^{\mathrm{a}}$ Data in $\mathrm{g} \cdot 100 \mathrm{~g}^{-1}$.

In the olive oil group, there were 5 males and 5 females; 4 males and 5 females in the flax oil group, and 3 males and 4 females in the fish oil group.

Table II shows the omega-3 fatty acid composition in $\mathrm{g} \cdot 100 \mathrm{~g}^{-1}$ of olive, flax and fish oils. Olive oil contained extremely low levels of $\alpha$-LNA, and no EPA, DHA or other omega-3 fatty acids. The $60 \mathrm{~g}$ daily dose of flax oil contained approximately $34 \mathrm{~g}$ of $\alpha$-LNA, but no measurable EPA or DHA. The daily dose of fish oil contained approximately $23 \mathrm{~g}$ of EPA and $12 \mathrm{~g}$ of DHA.

Table III shows the serum phospholipid fatty acid concentrations of subjects before and after supplementation with flax or fish oils, as a percentage of total fatty acids. There were no changes in serum phospholipid fatty acid status with olive oil supplementation. Flax oil supplementation resulted in a significant increase in $\alpha$-LNA $(206 \%)$ and a decrease in the AA/EPA ratio $(-43 \%)$. Fish oil supplementation resulted in increases in EPA (944\%), DHA (213\%), total omega3 fatty acids (289\%), and the omega-3/ omega-6 ratio $(392 \%)$. Decreases were noted in LA $(-24 \%), 20: 3 n-6(-39 \%)$, $22: 5 n-6(-67 \%)$, total omega- 6 fatty acids $(-23 \%)$, and the AA/EPA ratio $(-91 \%)$. Non-significant decreases were noted in AA in both the flax oil $(-10 \%)$ and fish oil $(-16 \%)$ groups. A non-significant increase was noted in EPA $(66 \%), 22: 5 n-3(63 \%)$ and total omega- 3 fatty acids (29\%) in the flax oil group.

There were no serious adverse events associated with consumption of any of the oils. Loose stool and fishy burps were noted by some individuals in both the flax and fish oil supplemented groups, and these side effects lessened throughout the supplementation period (data not shown).

\section{DISCUSSION}

This is the first study to examine the effect of high dose flax oil and fish oil on serum phospholipid fatty acid status in adults. For this study, adults with ADHD were the population of choice. Approximately $75 \%$ of adults with ADHD suffer from other psychiatric disorders such as bipolar mood disorders, schizophrenia, depression and dyslexia [28, 30-36], and these and other neuropsychiatric conditions are associated with decreased fish consumption and/or decreased omega-3 fatty acid levels in blood serum or RBC [10-14, $16,17,37-41]$. ADHD is also frequently comorbid with CHD [28]. In this study, the individuals with ADHD were not diagnosed with other psychiatric disorders, but this possibility cannot be ruled out. Furthermore, recent studies suggest that both children [21-23] and adults [24] with ADHD have altered fatty acid status, including decreased EPA and/or DHA. 
Table III. Serum phospholipid fatty acid analysis of select fatty acids of individuals before and after supplementation with flax or fish oil ${ }^{1}$.

\begin{tabular}{|c|c|c|c|c|c|c|c|}
\hline Fatty acid & Olive oil & Olive oil & Flax oil & Flax oil & Fish oil & Fish oil & $P$ val \\
\hline & & 12 & & & Bas & $12 \mathrm{v}$ & \\
\hline & $N=10$ & $N=10$ & $N=9$ & $N=9$ & $N=7$ & $N=7$ & \\
\hline C16:0 & $26.7 \pm 0.7$ & $26.9 \pm 0.7$ & $26.6 \pm 0.7$ & $26.6 \pm 0.6$ & $26.2 \pm 0.6$ & $26.4 \pm 0.9$ & 0.95 \\
\hline C18:0 & $13.7 \pm 0.3$ & $13.0 \pm 0.5$ & $13.2 \pm 0.5$ & $13.4 \pm 0.6$ & $13.6 \pm 0.5$ & 14.0 & 0.16 \\
\hline C18:1 & $12.4 \pm 0.2$ & $12.7 \pm 0.5$ & $12.1 \pm 0.5$ & $11.4 \pm 0.4$ & $12.2 \pm 0.6$ & $11.0 \pm 0.6$ & 0.12 \\
\hline C18:2n6 & $21.7 \pm 1.3^{\mathrm{a}}$ & $21.0 \pm 0.7^{\mathrm{a}}$ & $21.4 \pm 1.0^{\mathrm{a}}$ & $21.3 \pm 1.0^{\mathrm{a}}$ & $22.2 \pm 0.6^{\mathrm{a}}$ & $16.9 \pm 1.2^{b}$ & $<0.001$ \\
\hline $\mathrm{C} 18: 3 \mathrm{n} 3$ & $0.3 \pm 0.0^{\mathrm{a}}$ & $0.2 \pm 0.0^{\mathrm{a}}$ & $0.3 \pm 0.1^{\mathrm{a}}$ & $0.7 \pm 0.2^{b}$ & $0.3 \pm 0.1^{\mathrm{a}}$ & $0.2 \pm 0.0^{\mathrm{a}}$ & 0.04 \\
\hline C20:3n6 & $2.8 \pm 0.3^{\mathrm{a}}$ & $2.8 \pm 0.3^{\mathrm{a}}$ & $2.8 \pm 0.2^{\mathrm{a}}$ & $2.6 \pm 0.2^{\mathrm{a}}$ & $3.1 \pm 0.2^{\mathrm{a}}$ & $1.9 \pm 0.3^{\mathrm{b}}$ & 0.004 \\
\hline $\mathrm{C} 20: 4 \mathrm{r}$ & $9.9 \pm 0.4$ & $9.8 \pm 0.4$ & $10.0 \pm 0.3$ & $9.0 \pm 0.4$ & $9.9 \pm 0.6$ & 8.3 & 0.12 \\
\hline C20:5n3 EPA & $0.8 \pm 0.1^{\mathrm{a}}$ & $0.8 \pm 0.2^{\mathrm{a}}$ & $0.9 \pm 0.1^{\mathrm{a}}$ & $1.4 \pm 0.1^{\mathrm{a}}$ & $0.6 \pm 0.1^{\mathrm{a}}$ & $5.8 \pm 0.9^{b}$ & $<0.001$ \\
\hline C22:0 & $1.5 \pm$ & $1.1 \pm$ & 1.4 & 1.3 & $1.6 \pm$ & 0.1 & 0.28 \\
\hline C22:4n6 & $0.5 \pm 0.1$ & $1.1 \pm 0.1$ & $0.5 \pm 0.1$ & $0.8 \pm 0.1$ & $0.6 \pm 0.1$ & $0.8=$ & 0.17 \\
\hline $\mathrm{C} 22: 5 \mathrm{n} 6$ & $0.3 \pm 0.1^{\mathrm{a}}$ & $0.4 \pm 0.0^{\mathrm{a}}$ & $0.3 \pm 0.0^{\mathrm{a}}$ & $0.2 \pm 0.0^{\mathrm{a}}$ & $0.4 \pm 0.1^{\mathrm{a}}$ & $0.1 \pm 0.0^{\mathrm{b}}$ & 0.01 \\
\hline $\mathrm{C} 22: 5 \mathrm{n} 3$ & $1.0 \pm 0.1$ & $1.5 \pm 0.2$ & $1.0 \pm 0.1$ & $1.7 \pm 0.3$ & $1.0 \pm 0.1$ & 1.9 & 0.31 \\
\hline C22:6n3 DHA & $2.4 \pm 0.2^{\mathrm{a}}$ & $2.6 \pm 0.3^{\mathrm{a}}$ & $3.2 \pm 0.5^{\mathrm{a}}$ & $3.1 \pm 0.4^{\mathrm{a}}$ & $2.5 \pm 0.3^{\mathrm{a}}$ & $5.3 \pm 0.5^{b}$ & $<0.001$ \\
\hline C24:0 & $1.2 \pm 0.2$ & $1.2 \pm 0.1$ & $1.2 \pm 0.1$ & $1.4 \pm 0.1$ & $1.1 \pm 0.1$ & $1.4 \pm$ & 0.32 \\
\hline $\mathrm{C} 24: 1$ & $1.5 \pm 0.2$ & $2.0 \pm 0.1$ & 1.7 & 2.1 & $1.4 \pm 0.2$ & 2.0 & 0.90 \\
\hline Saturated & $44.5 \pm 1.0$ & $43.5 \pm 0.5$ & $43.9 \pm 0.3$ & $43.9 \pm 0.2$ & $43.9 \pm 0.3$ & 44.5 & 0.42 \\
\hline Monounsaturated & $15.0 \pm 0.1$ & $15.7 \pm 0.4$ & $14.8 \pm 0.5$ & $14.3 \pm 0.4$ & $14.5 \pm 0.5$ & $13.7 \pm 0.6$ & 0.07 \\
\hline Polyun & $40.5 \pm 1.1$ & $40.8 \pm 0.6$ & $41.3 \pm 0.6$ & $41.8 \pm 0.0 .5$ & $41.6 \pm 0.5$ & $41.9 \pm 0.5$ & 0.98 \\
\hline Total Omega-3 & $4.7 \pm 0.3^{\mathrm{a}}$ & $5.3 \pm 0.6^{\mathrm{a}}$ & $5.7 \pm 0.5^{\mathrm{a}}$ & $7.4 \pm 0.6^{\mathrm{a}}$ & $4.7 \pm 0.4^{\mathrm{a}}$ & $13.5 \pm 1.4^{\mathrm{b}}$ & $<0.001$ \\
\hline Total Omega-6 & $35.8 \pm 1.1^{\mathrm{a}}$ & $35.5 \pm 0.3^{\mathrm{a}}$ & $35.6 \pm 0.8^{\mathrm{a}}$ & $34.4 \pm 0.5^{\mathrm{a}}$ & $36.9 \pm 0.2^{\mathrm{a}}$ & $28.4 \pm 1.2^{\mathrm{b}}$ & $<0.001$ \\
\hline $\mathrm{Om}$ & $0.1 \pm 0.0^{\mathrm{a}}$ & $0.1 \pm 0.0^{\mathrm{a}}$ & $0.2 \pm 0.0^{\mathrm{a}}$ & $0.2 \pm 0.0^{\mathrm{a}}$ & $0.1 \pm 0.0^{\mathrm{a}}$ & $0.5 \pm 0.1^{b}$ & $<0.001$ \\
\hline & & & & & & & \\
\hline AA/EPA & $12.4 \pm 1.9^{\mathrm{a}}$ & $12.3 \pm 2.3^{\mathrm{a}}$ & $11.1 \pm 1.8^{\mathrm{a}}$ & $6.4 \pm 0.9^{b}$ & $16.5 \pm 2.5^{\mathrm{a}}$ & $1.4 \pm 0.6^{\mathrm{c}}$ & $<0.001$ \\
\hline
\end{tabular}

${ }^{1}$ Data expressed as wt $\%$ of total fatty acids. Values represent mean \pm SEM.

Differing superscripts $(\mathrm{a}, \mathrm{b}, \mathrm{c})$ across individual rows indicate significant differences $(P<0.05)$ between interventions.

The cause of the observed abnormalities of fatty acids in sufferers of ADHD is unknown, although there are several possible explanations. Serum phospholipid fatty acids reflect the dietary intakes of the past few days, and levels of serum phospholipid EPA and DHA have been shown to be correlated with fish consumption [42, 43], which suggests that the low levels of longchain omega- 3 fatty acids observed in studies of both children and adults with ADHD may be related to inadequate dietary intake. Also, the essential fatty acids must undergo complex biotransformation in order to be converted into their long-chain derivatives, and individuals vary in the efficiency of their conversion mechanisms [44]. Furthermore, children with ADHD show evidence of increased omega-3 fatty acid oxidation [45]. Therefore, there is evidence linking various environmental and metabolic factors with fatty acid levels in sufferers of ADHD.

Dietary intake of omage- 3 fatty acids has been positively correlated with health in terms of decreased risk of CHD [2-6] and various neuropsychiatric disorders [10-14, $16,17,37-41]$. The high seafood intake by 
the Japanese and Greenland Inuit has resulted in low ratios of n- 6 AA to n-3 EPA, with the Japanese showing AA/EPA ratios of approximately 1.7 and the Greenland Inuit showing ratios of less than 1 [9]. The baseline AA/EPA ratio in our study was 15.4; approximately 9 fold higher than that of the Japanese. AA/EPA ratios of 11.6 (healthy omnivores), 16.7 (healthy vegetarians), 11 (healthy individuals of Asian Indian descent), and 12.4 (healthy women) have been noted by our group in the past [46-48].

In this study, adults with ADHD were supplemented with high doses of olive, flax or fish oil. The goal of this study was to reduce the AA/EPA ratio to that found in populations which consume large quantities of marine food, such as the Japanese or Greenland Inuit. High dose fish oil was chosen given the high initial AA/EPA ratio (average 15.4) and the high risk for omega-3 oxidation [45]. As expected, there were no changes in serum fatty acid composition with olive oil supplementation, given the common consumption of many of the fatty acids in this oil in the North American diet. Flax oil supplementation resulted in minor changes in omega-3 fatty acid levels, mainly the short-chain fatty acid $\alpha$-LNA. These results are consistent with earlier publications suggesting increases in plasma $\alpha$-LNA with both flax seed $[49,50]$ and flax oil [51, 52] supplementation of humans. Non-significant increases in the long-chain omega-3 fatty acids EPA and DPA with flax oil supplementation were also observed in this study. Previous work with flaxseed or flax oil supplementation resulted in increased plasma EPA and/or docosapentaenoic acid (DPA; 22:5n-3) [49-52]. A 10\%-100\% increase in EPA and 5\%-25\% increase in DPA with flax oil supplementation was noted in these studies [49-52], compared with the increase of $66 \%$ and $63 \%$ observed in our study, respectively. Flax oil supplementation caused a decrease in the AA/ EPA ratio to 6.4, 3.7 fold higher than the AA/EPA ratio observed in the Japanese population.
Fish oil supplementation resulted in changes in several measurements. First, there were significant increases in the longchain omega-3 fatty acids EPA and DHA. These results are in agreement with other studies in humans, in which healthy adults were supplemented with fish oil [29, 53]. In these studies, increases in EPA were between $500-600 \%$ as compared with the increase of $944 \%$ as observed herein. Increases in DHA were between 150-200\% as compared with the increase of approximately $213 \%$, as observed herein. Second, there was in increase in total omega- 3 fatty acids, which is of interest since it has been shown that children with the lowest levels of total omega-3 fatty acids display a greater number of behavior, learning and health problems [23]. Third, there was an increase in the omega-3/omega-6 ratio, and decreases in certain omega- 6 fatty acids (18:2n-6, 20:3n-6, 22:5n-6). Higher levels of omega- 6 fatty acids show a direct association with cognitive decline due with aging, while the ratio of omega- 3 to omega- 6 fatty acids shows an inverse association [54], which suggests that the decrease in omega- 6 fatty acids and the increase in the omega-3/omega-6 ratio observed with fish oil supplementation in this study may have a positive influence on cognitive function. Perhaps most importantly, there was a substantial decrease in the AA/EPA ratio, which has been directly correlated with the severity of depressive symptoms in patients with moderate to severe depression [55], a condition which shows a high degree of comorbidity with ADHD [28]. While flax oil also caused a decrease in this ratio, the effect of fish oil on this measure was much greater and resulted in an AA/EPA ratio equivalent to that observed in the Japanese population.

The difference in fatty acid changes with flax oil and fish oil supplementation in adults with ADHD are of interest given the presence of high DHA in the brain of humans, and the role of EPA in inflammation. While it is unclear whether peripheral LCPUFA composition reflects the phospholipid 
composition of neuronal membranes, preliminary data in schizophrenic patients does suggest a correlation [56]. Therefore, it is possible that the low levels of DHA observed in children and adults with ADHD may reflect low levels of DHA in neuronal membranes, and that correction of these levels might increase DHA in the brain. Since the efficiency of conversion of $\alpha$-LNA to DHA in healthy adults via elongation and desaturation has been estimated to be very low $[44,57]$, a dietary source of this fatty acid may be required. As evidenced by this study, even supplementation with very high levels of flax oil does not result in an increase in serum phospholipid DHA over a 12 weeksupplementation period, while supplementation with high levels of fish oil does.

At this time, there is no clear evidence to suggest that supplementation with omega-3 fatty acids is an effective treatment for ADHD, although it is known that such supplementation can modify blood phospholipid fatty acid levels in children [27]). In 2001, Voigt et al. treated children with the condition with the long-chain omega-3 fatty acid DHA (from an algal source) for a period of 4 months, and observed an increase in plasma DHA of $260 \%$. As of yet, there have been no trials investigating the effect of omega-3 fatty acid supplementation in adults with ADHD, and the current study is the first to report modification of fatty acid levels in this population through supplementation with sources of omega-3 fatty acids.

In conclusion, supplementation with a high dose fish oil-derived EPA and DHA concentrate resulted in an increase in the long-chain omega-3 fatty acids EPA and DHA, total omega-3 fatty acids and the omega-3/omega- 6 ratio, and a decrease in several omega- 6 fatty acids, and the AA/ EPA ratio to approximately the ratio observed in the Japanese, but not the Greenland Inuit. Flax oil supplementation resulted only in an increase in the short-chain omega-3 fatty acid $\alpha$-LNA and a smaller decrease in the AA/EPA ratio. Furthermore, the increase in
EPA and other omega-3 fatty acids observed with flax oil supplementation was not significant as compared with the changes observed with fish oil supplementation. While it is unknown whether such changes are correlated with an improvement in the signs and symptoms of ADHD, it is known that individuals with both the juvenile and adult form of the condition suffer from low levels of long-chain omega-3 fatty acids. Therefore, these data suggest that in order to optimize levels of these fatty acids in the serum phospholipids, as well as the AA/ EPA ratio, of adults with ADHD, high dose fish oil may be preferable to high dose flax oil. Future study is warranted to determine whether lower levels of EPA and DHA also accomplish this reduction in the AA/EPA ratio.

\section{ACKNOWLEGDEMENTS}

We would like to thank Adopt A Patient Foundation for funding this investigation. In addition, thanks go to John Barban, MSc and the many undergraduate volunteers of the Human Nutraceutical Research Unit at the University of Guelph for helping out with the investigation. Flax oil was donated by Bioriginal Food \& Science Corp. (Saskatoon, Sask) and fish oil was donated by Ocean Nutrition Canada (Mulgrave, N.S.).

\section{REFERENCES}

[1] Kris-Etherton PM, Shaffer D, Yu-Poth S, Huth P, Moriarty K, Fishell V, Hargrove RL, Zhao G, Etherton TD. Polyunsaturated fatty acids in the food chain in the United States. Am J Clin Nutr 2000, 71: S179-S188.

[2] Bang HO, Dyerberg J, Nielson AB. Plasma lipid and lipoprotein pattern in Greenlandic west-coast Eskimos. Lancet 1971, 1: 11431144.

[3] Bang HO, Dyerberg J. Plasma lipids and lipoproteins in Greenlandic West-coast Eskimos. Acta Med Scand 1972, 192: 85-94.

[4] Dyerberg J, Bang HO, Hjorne N. Fatty acid composition of the plasma lipids in Greenland Eskimos. Am J Clin Nutr 1975, 28: 958-966. 
[5] Hirai A, Terano T, Saito $H$, Tamura $Y$, Yoshida S. Clinical and epidemiological studies of eicosapentaenoic acid in Japan. In: Lands WEM (Ed), Polyunsaturated Fatty Acids and Eicosanoids, Champaign, IL, 1987, p 9-24.

[6] Kagawa Y, Nishizawa M, Suzuki M, Miyatake T, Hamamoto T, Goto K, Motonaga E, Izumikawa H, Hirata H, Ebihara A. Eicosapolyenoic acids of serum lipids of Japanese islanders with low incidence of cardiovascular diseases. J Nutr Sci Vitamin 1982, 28: 441453.

[7] Bang HO, Dyerberg J, Sinclair HM. The composition of the Eskimo food in north western Greenland. Am J Clin Nutr 1980, 33: 26572661.

[8] Holub BJ. Clinical nutrition: 4. Omega-3 fatty acids in cardiovascular care. CMAJ 2002, 166: 608-615.

[9] Hirai A, Hamazaki T, Terano T, Nishikawa T, Tamura Y, Sajiki J. Eicosapentaenoic acid and platelet function in Japanese (letter). Lancet 1980, 2: 1132-1133.

[10] Grant WB. Dietary links to Alzheimer Disease. Alzheimer Dis Rev 1997, 2: 42-55.

[11] Grant WB. Diet and risk of dementia: does fat matter? The Rotterdam study Neurology 2003, 60: 2020-2021.

[12] Kalmijn S, Feskens EJ, Launer LJ, Kromhout D. Polyunsaturated fatty acids, antioxidants, and cognitive function in very old men. Am J Epidemiol 1997, 145: 33-41.

[13] Kalmijn S, van Boxtel MPJ, Ocke M, Verschuren WMM, Kromhout D, Launer LJ. Dietary intake of fatty acids and fish in relation to cognitive performance at middle age. Neurology 2004, 52: 275-280.

[14] Morris MC, Evans DA, Bienias JL, Tangney CC, Bennett DA, Wilson RS, Aggarwal N, Schenider J. Consumption of fish and n-3 fatty acids and risk of incident Alzheimer's disease. Arch Neurol 2003, 60: 940-946.

[15] Hibbeln JR, Salem N. Dietary polyunsaturated fatty acids and depression: when cholesterol does not satisfy. Am J Clin Nutr 1995, 62: $1-9$.

[16] Noaghiul S, Hibbeln JR. Cross national relationship of seafood consumption and rates of bipolar disorders. Am J Psychiatry 2003, 160: 2222-2227.
[17] Tanskanen A, Hibbeln JR, Tuomilehto J, Uutela A, Haukkala A, Lehtonen J, Vartiainen E. Fish consumption and depressive symptoms in the general population in Finland. Psychiatr Serv 2001, 52: 529-531.

[18] Bromberger JT, Harlow S, Avis N, Kravitz HM, Cordal A. Racial/ethnic differences in the prevalence of depressive symptoms among middle-aged women: The Study of Women's Health Across the Nation (SWAN). Am J Public Health 2004, 94: 1378-1385.

[19] Krause N, Liang J. Cross-cultural variations in depressive symptoms in later life. Int Psychogeriatr 1992, 4 (Suppl 2): 185-202.

[20] O'Connor CM, Gurbel PA, Serebruany VL. Depression and ischemic heart disease. Am Heart J 2004, 140 (Suppl 4): 63-69.

[21] Stevens LJ, Zentall SS, Deck JL, Abate ML, Watkins BA, Lipp SR, Burgess JR. Essential fatty acid metabolism in boys with attentiondeficit hyperactivity disorder. Am J Clin Nutr 1995, 62: 761-768.

[22] Mitchell EA, Aman MG, Turbott SH, Manku M. Clinical characteristics and serum essential fatty acid levels in hyperactive children. Clin Pediatr 1986, 26: 406-411.

[23] Stevens LJ, Zentall SS, Abate L, Kuczek T, Burgess JR. Omega-3 fatty acids in boys with behavior, learning, and health problems. Physiol Behav 1996, 59: 915-920.

[24] Young GS, Maharaj NJ, Conquer JA. Blood phospholipid fatty acid analysis of adults with and without Attention Deficit/Hyperactivity Disorder. Lipids 2004, 39: 117-123.

[25] Hirayama S, Hamazaki T, Terasawa K. Effect of docosahexaenoic acid-containing food administration on symptoms of attention-deficit/hyperactivity disorder - a placebo-controlled double-blind study. Eur J Clin Nutr 2004, 58: 467-473.

[26] Stevens L, Zhang W, Peck L, Kuczek T, Grevstad N, Mahon A, Zentall SS, Arnold LE, Burgess J.R. EFA supplementation in children with inattention, hyperactivity, and other disruptive behaviours. Lipids 2003, 38: 1007 1021.

[27] Voigt RG, Llorente AM, Jensen CL, Fraley JK, Berretta MC, Heird WC. A randomized, double-blind, placebo-controlled trial of docosahexaenoic acid supplementation in children with attention-deficit/hyperactivity disorder. J Pediatr 2001, 139: 189-196. 
[28] Spencer T, Biederman J, Wilens T, Faraone SV. Adults with attention-deficit/hyperactivity disorder: a controversial diagnosis. J Clin Psychiatry 1998, 59 (Suppl 7): 59-68.

[29] Laidlaw M, Holub BJ. Effects of supplementation with fish oil-derived $n-3$ fatty acids and $\gamma$-linolenic acid on circulating plasma lipids and fatty acid profiles in women. Am J Clin Nutr 2003, 77: 37-42.

[30] Barr WB. Schizophrenia and attention deficit disorder. Two complex disorders of attention. Ann. NY Acad. Sci 2001, 931: 239-250.

[31] Biederman J, Faraone SV, Spencer T, Wilens T, Norman D, Lapey KA, Mick E, Lehman BK, Doyle A. Patterns of psychiatric comorbidity, cognition and psychosocial functioning in adults with attention deficit hyperactivity disorder. Am J Psychiatry 1993, 150: 1792-1798.

[32] Clarke AR, Barry RJ, McCarthy R, Selikowitz $M$. EEG analysis of children with attentiondeficit/hyperactivity disorder and comorbid reading disabilities. J Learn Disabil 2002, 35: 276-285.

[33] Fischer M, Barkley RA, Smallish L, Fletcher K. Young adult follow-up of hyperactive children: self-reported psychiatric disorders, comorbidity, and the role of childhood common problems and teen CD. J Abnorm Child Psychol 2002, 31: 463-375.

[34] Hesslinger B, Tebartz van Elst L, Mochan F, Ebert D. A psychopathological study into the relationship between attention deficit hyperactivity disorder in adult patients and recurrent bipolar depression. Acta Psychiatr Scand 2003, 107: 385-389.

[35] Tramontina S, Schmitz M, Polanczyk G, Rohde LA. Juvenile bipolar disorder in Brazil: clinical and treatment findings. Biol Psychiatry 2003, 53: 1043-1049.

[36] Willcutt EG, Pennington BF. Comorbidity of reading disability and attention-deficit/hyperactivity disorder: differences by gender and subtype. J Learn Disabil 2000, 33: 179-191.

[37] Arvindakshan M, Sitasawad S, Debsikdar V, Ghate M, Evans D, Horrobin DF, Bennett C, Ranjekar PK, Mahadik SP. Essential polyunsaturated fatty acid and lipid peroxide levels in never-medicated and medicated schizophrenia patients. Biol Psychiatry 2003, 53: 56-64.

[38] Assies J, Lieverse R, Vreken P, Wanders RJ, Dingemans PM, Linszen DH. Significantly reduced docosahexaenoic and docosapentaenoic acid concentrations in erythrocyte membranes from schizophrenic patients compared with a carefully matched control group. Biol Psychiatry 2001, 49: 510-522.

[39] Conquer JA, Tierney MC, Zecevic J, Bettger WJ, Fisher RH. Fatty acid analysis of blood plasma of patients with Alzheimer's disease, other types of dementia, and cognitive impairment. Lipids 2000, 35: 1305-1312.

[40] Mellor JE, Laugharne JDE, Peet M. Omega3 fatty acid supplementation in schizophrenia patients. Hum. Psychopharmacol 1996, 11: 39-46.

[41] Taylor KE, Higgins CJ, Calvin CM, Hall JA, Easton T, McDaid AM, Richardson AJ. Dyslexia in adults is associated with clinical signs of fatty acid deficiency. Prostaglandins Leukot Essent Fat Acids 2000, 63: 75-78.

[42] Bjerve KS, Brubakk AM, Fougner KJ, Johnsen H, Midthjell K, Vik T. Omega-3 fatty acids: essential fatty acids with important biological effects, and serum phospholipid fatty acids as markers of dietary omega 3-fatty acid intake. Am J Clin Nutr 1993, 57: 801S-805S.

[43] Hjartaker J, Lund E, Bjerve KS. Serum phospholipid fatty acid composition and habitual intake of marine foods registered by a semiquantitative food frequency questionnaire. Eur J Clin Nutr 1997, 51: 736-742.

[44] Emken EA, Adolf RO, Gulley RM. Dietary linoleic acid influences desaturation and acylation of deuterium-labeled linoleic and linolenic acids in young adult males. Biochim Biophys Acta 1994, 1213: 277-288.

[45] Ross BM, McKenzie I, Glen I, Bennett CP. Increased levels of ethane, a non-invasive marker of n-3 fatty acid oxidation, in breath of children with attention deficit hyperactivity disorder. Nutr Neurosci 2003, 6: 277-281.

[46] Conquer JA, Holub BJ. Dietary docosahexaenoic acid as a source of eicosapentaenoic acid in vegetarians and omnivores. Lipids 1997, 32: $341-345$

[47] Conquer JA, Holub BJ. Effect of supplementation with different doses of DHA on the levels of circulating DHA as non-esterified fatty acid in subjects of Asian Indian background. Lipids 1998, 39: 286-292.

[48] Conquer JA, Roelfsema H, Zecevic J, Graham TE, Holub BJ. Effect of exercise on FA profiles in n-3 supplemented and nonsupplemented premenopausal women. Lipids 2002, 37: 947-951. 
[49] Clark WF, Parbtani A, Huff MW, Spanner E, de Salis H, Chin-Yee I, Philbrick D, Holub BJ. Flaxseed: a potential treatment for lupus nephritis. Kidney Int 1995, 48: 475-480.

[50] Tarpila S, Aro A, Salminen I, Tarpila A, Kleemola P, Akkila J, Aldercreutz $\mathrm{H}$. The effect of flax seed supplementation in processed foods on serum fatty acids and enterolactone. Eur J Clin Nutr 2002, 56: 157-165.

51] Chan JK, McDonald BE, Gerrard JM, Bruce VM, Weaver BJ, Holub BJ. Effect of dietary alpha-linolenic acid and its ratio to linoleic acid on platelet and plasma fatty acids and thromobogenesis. Lipids 1993, 28: 811-817.

[52] Sanders TA, Hinds A, Pereira CC. Influence of n-3 fatty acids on blood lipids in normal subjects. J Intern Med 1989, 225 (Suppl): 99 104.

[53] Stark KD, Park EJ, Maines VA, Holub BJ. Effect of a fish-oil concentrate on serum lipids in postmenopausal women receiving and not receiving hormone replacement therapy in a placebo-controlled, double-blind trial. Am J Clin Nut. 2000, 72: 389-394.

[54] Heude B, Ducimetiere P, Berr C. Cognitive decline and fatty acid composition of erythrocyte membranes - The EVA Study. Am J Clin Nutr 2003, 77: 803-808.

[55] Adams PB, Lawson S, Sanigorski A, Sinclair AJ. Arachidonic acid to eicosapentaenoic acid ratio in blood correlates positively with clinical symptoms of depression. Lipids 1996, 31 (suppl): S157-S161.

[56] Yao J, Stanley JA, Reddy RD, Keshavan MS Pettegrew JW. Correlations between peripheral polyunsaturated fatty acid content and in vivo membrane phospholipid metabolites. Biol Psychiatry 2002, 15: 823-830.

[57] Pawlosky RJ, Hibbeln JR, Novotny JA, Salem NJ. Physiological compartmental analysis of alpha-linolenic acid metabolism in adult humans. J. Lipid Res 2001, 142: 1257-1265. 